\title{
Served straight up: Effects of verticality cues on taste evaluations and luxury perceptions
}

\author{
Thomas J.L. van Rompay*, Joris J. van Hoof, Jens Rorink, Marloes Folsche \\ University of Twente, the Netherlands
}

\section{A R T I C L E I N F O}

\section{Keywords:}

Embodied cognition

Sensation transfer

Visual communication

Advertising design

Graphic design

Taste experience

\begin{abstract}
A B S T R A C T
Based on the embodied cognition framework and research addressing transfer effects between visual perception and taste, the point of departure for this study is the widespread association between vertical orientation and connotations related to luxury and (economic) power. Specifically, this study tests whether vertical orientation not only affects impressions of product luxury, but also influences actual taste evaluations, including perceptions of taste strength (intensity) and taste liking. Results confirm these predictions by showing that participants in a Dutch coffee house gave higher ratings on these constructs when they were exposed to an ad display depicting vertically-oriented rather than horizontally-oriented visual cues during a coffee sample test. Findings furthermore stress the influence of design cues as opposed to more traditional product claims. Implications for marketing and design practice are discussed.
\end{abstract}

In 2009, Nespresso launched their 'Citiz: High Design by Nespresso' campaign. With their coffee machine set against a background of towering skyscrapers, the Nespresso brand was positioned as a high quality, stylish and luxurious brand; a 'luxury' strategy appealing to an ever-larger segment of consumers (Kapferer \& Bastien, 2009; Kastanakis \& Balabanis, 2012). Although also reinforced by the skyscrapers (depicted throughout the campaign's advertisements) and connotations of city life and glamour, the reference to 'high' in the campaign slogan was, in all likelihood, anything but trivial. To provide a first indication of its importance, consider for instance phrases such as a high-end restaurant, an up-scale fashion store, or an uptown girl. Such phrases reveal a widespread association between verticality (i.e., 'high', 'up') on the one hand, and meanings reflective of (economic) power such as luxury, quality, and exclusivity on the other (Lakoff \& Johnson, 1980).

Not only is this relationship language-independent (Lakoff \& Johnson, 1999), research clearly shows this relationship to apply to visual displays and objects as well (Machiels \& Orth, 2017; Van Rompay, Bontekoe, De Vries, \& Tanja-Dijkstra, 2012; Van Rompay \& Pruyn, 2011). For instance, Van Rompay and Pruyn (2011) demonstrated that a fictitious bottled water brand is more readily perceived as luxurious, and elicits higher price expectations, when it comes in a tall, elongated bottle shape rather than in a more compact bottle shape. Machiels and Orth (2017) illustrated how perceptions of verticality may also be induced through the environmental context. Specifically, their findings showed that consumers' quality perceptions are enhanced when a package is placed on a shelf that is vertically rather than horizontally orientated. And of particular relevance to the current undertaking, Van Rompay, De Vries, Bontekoe, and Tanja-Dijkstra (2012) demonstrated that orientation of advertising imagery can influence luxury perceptions and price expectations of advertised products: cosmetics were perceived as more luxurious, appealing, and of a higher price when pitted against a vertically, rather than a horizontally oriented, background.

The central question in the current study is whether verticality effects also translate to actual product experiences. Specifically, to what degree do visual advertising cues not only influence (cognitive) impressions and associations related to quality and luxury, but also affect actual taste evaluations? In other words, do power-related associations (perceptions of luxury) triggered by visual appearance also enhance evaluations of taste strength and (considering the general appeal of a luxury strategy to consumers) taste liking? To explore these relationships, a coffee taste sample test was conducted at a coffeehouse in which customers tasted a black coffee while exposed to an advertisement (for the respective fictitious brand) either depicting vertical or horizontal lines. Before presenting the details of this study, we will first elaborate on the key notions involved.

\section{Verticality and consumer experience}

Why do we associate verticality with power-related constructs such

\footnotetext{
* Corresponding author. University of Twente, Department of Communication Science, P.O. Box 217, 7500, AE Enschede, the Netherlands.

E-mail address: t.j.l.vanrompay@utwente.nl (T.J.L. van Rompay).
} 
as luxury (financial or economic power) and dominance (social power)? The line of reasoning presented in this paper is inspired by early work in visual aesthetics (e.g., Arnheim, 1974) and the embodied cognition framework. This framework was originally developed in the field of cognitive linguistics (Lakoff \& Johnson, 1980; 1999), and subsequently fine-tuned and tested in the domains of cognitive and social psychology (e.g., Barsalou, 1999; 2008) and design research (e.g., Van Rompay, Hekkert, Saakes, \& Russo, 2005; Van Rompay \& Ludden, 2015). With respect to embodiment in design, the core assumption holds that in order to understand why specific look and feel properties of products call forth specific evaluations and (sensory) experiences, we have to go back to primary, bodily experiences and related body-environment interactions.

In the case of verticality, think of going upwards (as when cycling up a hill) which requires effort and overcoming of gravitational forces pushing us down. This very fundamental experience (we all are through and through acquainted with) makes us look up at heights with a sense of awe and respect, and at the same time makes us understand linguistic phrases such as 'she is climbing the social ladder' or 'she is a rising star' as referring to a successful individual. In other words, such expressions are rooted in our own physical interactions in and with the environment where movement in the vertical plane is linked to strength and perseverance. As illustrated by these examples, this embodied, physical basis underlies more metaphorical or abstract uses of power including social power and, as discussed earlier, financial or economic power (e.g., luxury perceptions; e.g., Van Rompay et al., 2012).

In line with these notions, several studies have demonstrated effects of vertical orientation on consumer responses (e.g., Machiels \& Orth, 2017; Peracchio \& Meyers-Levy, 2005; Van Rompay et al., 2012). For instance, Van Rompay et al. (2012) distinguished between vertically and horizontally-oriented lines in the advertising background, and showed that (in line with the Nespresso example) vertical lines enhanced product perceptions reflective of economic power (i.e., luxurious, exclusive, chic). Likewise, Peracchio \& Meyers-Levy (2005) showed that a vertical, rather than a slanted, orientation of a product depicted in an ad enhances perceptions of prestige and luxury. Finally, Raghubir and Krishna (1999) showed that container height or elongation not only affects preference and choice, but is also used as a heuristic cue for making volume judgments (with taller packages appearing to be more voluminous).

As discussed, vertically cues may also influence product evaluations when displayed in the surrounding environment (Machiels \& Orth, 2017). In line with this finding, a considerable body of research attests to the influence of extrinsic cues figuring in the consumption context (see Piqueras-Fiszman \& Spence, 2015, for a review). For instance, based on research demonstrating a relationship between shape angularity and connotations of power and confrontation (Arnheim, 1974; Zhang, Feick, \& Price, 2006), in Becker, van Rompay, Schifferstein, and Galetzka (2011), customers at a supermarket were exposed to an animation (presented on a computer screen) of either a rounded or angular product package for a new (fictitious) yoghurt brand, and next sampled the yoghurt. Findings showed that exposure to the package presented on screen influenced taste intensity ratings of the yoghurt sampled next, with the angular package boosting intensity ratings (see Velasco, Woods, Petit, Cheok, \& Spence (2016) for a review on shape-taste correspondences).

Such sensation transfer effects (e.g., Skaczkowski, Durkin, Kashima, \& Wakefield, 2016) usually involve an automatic process in which consumers draw on initial impressions from one modality (e.g., visual perception) which steer subsequent evaluations in another modality (e.g., product taste; Huber \& McCann, 1982; Pinson, 1986). In other words, expectations formed prior to tasting (e.g., seeing and feeling a rough package and expecting a crispy taste) can influence subsequent taste experiences (e.g., actually experiencing biscuits as being crispier when sampled from a rough, as opposed to a smooth, package; Piqueras-Fiszman \& Spence, 2012).
Such effects are indicative of so-called crossmodal correspondences, defined as tendencies for certain sensory features or dimensions from one sensory modality (e.g., vision or touch) to be associated with sensory features or dimensions in another modality (e.g., smell or taste; see Spence, 2011, pp. 971-995 for a review). When looking for structural determinants underlying crossmodal correspondences (e.g., what are common dimensions across various sensory modalities?), intensity has been frequently pointed out as such an 'amodal' dimension (Becker et al., 2011; Deroy, Crisinel, \& Spence, 2013; Osgood, Suci, \& Tannenbaum, 1957). Thus, the finding that an angular shape induces perceptions of a strong taste (Becker et al., 2011) can be explained by the fact that intensity is a common dimension of both visual perception (perceiving an angular shape as strong or potent) and taste experience (evaluating a taste as strong or intense).

In sum, based on embodied cognition literature, a relationship between orientation of visual cues and meaning attributions is proposed, with a vertical orientation generating perceptions of (economic) power (i.e., luxury and quality perceptions). Additionally, previous research on sensation transfer effects and crossmodal correspondences leads us to propose that such associations will transfer to taste. Hence, we will study whether verticality cues (vertical or horizontal lines in a promotional display for a fictitious coffee brand) affect luxury and related quality evaluations and taste evaluation. Starting with luxury and related quality evaluations, we expected that:

H1a: An ad display portraying vertically oriented, rather than horizontally-oriented, visual cues enhances product luxury evaluations.

H1b: An ad display portraying vertically oriented, rather than horizontally-oriented, visual cues enhances product quality evaluations.

In addition to luxury and quality evaluations, two taste evaluation hypotheses are proposed. Specifically, as verticality has been shown to influence perceptions of power or strength (e.g., Schubert, 2005), and as intensity (conceptually related to power and strength) is a common dimension across sensory modalities (e.g., Deroy et al., 2013), we were particularly interested in exploring whether effects of verticality cues would extend to taste intensity evaluations. Note that such transfer effects would be in line with previous studies on crossmodal correspondences in which expectations based on (visual) perception of the stimulus steer subsequent sensory evaluations (e.g., Becker et al., 2011; Deroy et al., 2013; Spence, 2011, pp. 971-995). Hence:

H2a: An ad display portraying vertically oriented, rather than horizontally-oriented, visual cues enhances taste intensity.

Additionally, we were interested in exploring whether vertical orientation would also enhance taste liking. That is, considering the general appeal of a luxury strategy to consumers (Kapferer \& Bastien, 2009; Kastanakis \& Balabanis, 2012), and previous research showing that enhanced luxury perceptions also transpire in enhanced product evaluations (e.g., a more positive product attitude; Van Rompay et al., 2012), we expected that:

H2b: An ad display portraying vertically oriented, rather than horizontally-oriented, visual cues enhances taste liking (via perceptions of luxury).

Along similar lines, we will test whether (verticality-induced) luxury perceptions also transpire in a higher purchase intention (indicative of a positive product evaluation). Hence:

H3: An ad display portraying vertically oriented, rather than horizontally-oriented, visual cues enhances purchase intentions (via perceptions of luxury).

On a more explorative level, we were interested in studying whether vertical orientation would also heighten key benefits of coffee consumption, including increased alertness, concentration, focus, and arousal. That is, a stronger taste (indicative of higher caffeine levels) might well bring these consequences of product usage better to the fore. Hence:

H4: An ad display portraying vertically oriented, rather than horizontally-oriented, visual cues enhances taste consequences.

In addition to studying effects of visual cues, a basic blend or 
exclusive blend brand stamp (i.e., claim) was also presented on the package in order to study the relative persuasiveness of both types of cues. That is, in contrast to a product claim through which meanings are communicated explicitly by advertisers, visual, non-figurative (verticality) cues arguably induce more implicit consumer-generated attributions of brand meaning (cf. Deng \& Kahn, 2009; Krishna, 2012; Peracchio \& Meyers-Levy, 2005).

In addition to studying the relative persuasiveness of both types of cues, of additional relevance here is the question what happens when visual cues and claim (mis)match. That is, impression formation (of product characteristics and related benefits) should be hampered when meanings communicated by claim clash with those connoted through visuals, a prediction in line with processing fluency accounts which suggest that ease of processing positively affects stimulus evaluations (Reber, Schwarz, \& Winkielman, 2004; Van Rompay, Pruyn, \& Tieke, 2009).

For instance, Van Rompay et al. (2009) tested responses to ad displays for a fictitious brand of soft drinks in which either congruent combinations of product appearance and slogan were presented (i.e., a 'natural' looking bottle shape accompanied by a slogan stressing naturalness) or incongruent combinations (i.e., a natural bottle shape paired with a slogan suggestive of an artificially-sweetened soft drink). Findings showed that product evaluations were more positive for congruent, as opposed to incongruent, product shape-slogan combinations. Hence, we propose that:

H5: Matching combinations of design cue and claim (i.e., verticallyoriented imagery in combination with an exclusive blend, rather than a basic blend, brand claim) enhance taste liking and purchase intention.

In order to test these hypotheses, a 2 (ad display: vertical versus horizontal orientation) X 2 (claim: exclusive blend versus basic blend) between-subject design was employed. The experiment was conducted at a coffeehouse where customers took part in a coffee taste sample test.

\section{Method}

\subsection{Pretest}

A pretest was conducted in order to develop the ad display and to select the product claim. For the verticality design ten 'high' designs (see Fig. 1) were evaluated by an online sample of 100 participants who rated these displays (using 5-point rating scales) on the extent to which
Table 1

Result of the pretest.

\begin{tabular}{|c|c|c|c|c|}
\hline Display & luxury & prestige & chicness & dominance \\
\hline \multirow[t]{2}{*}{1} & $M=2.06$ & $M=2.20$ & $M=2.26$ & $M=2.52$ \\
\hline & $S D=.96$ & $S D=1.09$ & $S D=1.08$ & $S D=1.07$ \\
\hline \multirow[t]{2}{*}{2} & $M=3.56$ & $M=3.38$ & $M=3.42$ & $M=3.50$ \\
\hline & $S D=1.01$ & $S D=1.01$ & $S D=.91$ & $S D=1.06$ \\
\hline \multirow[t]{2}{*}{3} & $M=2.70$ & $M=2.64$ & $M=2.88$ & $M=3.00$ \\
\hline & $S D=1.11$ & $S D=1.06$ & $S D=1.19$ & $S D=.99$ \\
\hline \multirow[t]{2}{*}{4} & $M=2.44$ & $M=2.62$ & $M=2.40$ & $M=2.66$ \\
\hline & $S D=1.05$ & $S D=1.05$ & $S D=.99$ & $S D=1.12$ \\
\hline \multirow[t]{2}{*}{5} & $M=3.04$ & $M=3.08$ & $M=3.28$ & $M=3.34$ \\
\hline & $S D=1.12$ & $S D=1.10$ & $S D=.99$ & $S D=.94$ \\
\hline \multirow[t]{2}{*}{6} & $M=2.74$ & $M=2.68$ & $M=2.64$ & $M=2.70$ \\
\hline & $S D=1.12$ & $S D=1.00$ & $S D=.90$ & $S D=1.09$ \\
\hline \multirow[t]{2}{*}{7} & $M=3.42$ & $M=3.30$ & $M=3.36$ & $M=3.18$ \\
\hline & $S D=1.05$ & $S D=1.09$ & $S D=1.03$ & $S D=1.08$ \\
\hline \multirow[t]{2}{*}{8} & $M=3.08$ & $M=3.34$ & $M=3.20$ & $M=3.10$ \\
\hline & $S D=1.03$ & $S D=.94$ & $S D=.93$ & $S D=.97$ \\
\hline \multirow[t]{2}{*}{9} & $M=2.70$ & $M=2.76$ & $M=2.86$ & $M=2.92$ \\
\hline & $S D=1.07$ & $S D=.92$ & $S D=1.01$ & $S D=.94$ \\
\hline \multirow[t]{2}{*}{10} & $M=2.76$ & $M=2.88$ & $M=3.02$ & $M=2.70$ \\
\hline & $\mathrm{SD}=.96$ & $S D=.87$ & $S D=1.02$ & $S D=.97$ \\
\hline
\end{tabular}

Note: display numbers correspond to display variants presented in Fig. 1.

Table 2

Participant demographics as a function of experimental condition.

\begin{tabular}{lllll}
\hline Condition & Male & Female & \multicolumn{2}{l}{ Age } \\
\cline { 2 - 5 } & $\mathrm{n}$ & $\mathrm{n}$ & \multirow{2}{*}{$M$} & \multicolumn{2}{l}{$S D$} \\
\hline Vertical display/exclusive claim & 20 & 10 & 23.00 & 6.37 \\
Vertical display/basic claim & 13 & 17 & 22.67 & 7.88 \\
Horizontal display/exclusive claim & 16 & 14 & 20.83 & 2.67 \\
Horizontal display/basic claim & 21 & 9 & 25.90 & 10.41 \\
\hline
\end{tabular}

these connote luxury, prestige, chicness, and dominance. Mean comparisons revealed that the (from left to right) second display presented in the top row (see Fig. 1) received the highest scores on all four items (see Table 2).

Likewise, to select the most appropriate product claim, ten 'quality' claims (e.g., premium, excellent, exclusive) and ten 'regular' claims (e.g., basic, regular, standard) were selected and presented to the same sample

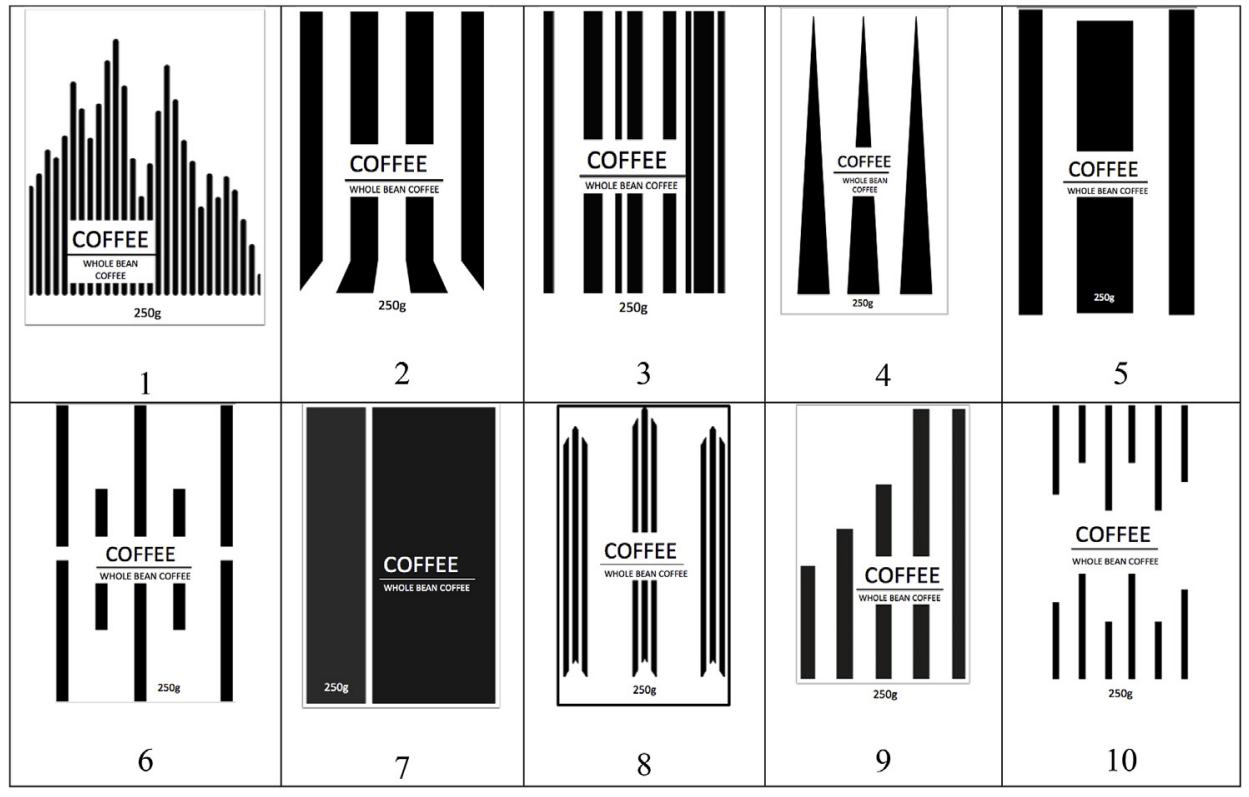

Fig. 1. The ten verticality display variants used in the pretest. 
Table 3

Mediation analyses (taste liking).

\begin{tabular}{lccc}
\hline Variable & $\beta$ & $t$ & $p$ \\
\hline $\begin{array}{l}\text { Regression 1 (DV: taste liking) } \\
\text { Ad display }\end{array}$ & .38 & 4.46 & $<.001$ \\
$\begin{array}{l}\text { Regression 2 (DV: perceived luxury) } \\
\text { Ad display }\end{array}$ & .38 & & $<.001$ \\
$\begin{array}{l}\text { Regression 3 (DV: taste liking) } \\
\text { Perceived luxury }\end{array}$ & .51 & & \\
Ad display & .19 & 6.45 & .02 \\
\hline
\end{tabular}

Table 4

Mediation analyses (purchase intention).

\begin{tabular}{llll}
\hline \multicolumn{1}{l}{$\begin{array}{l}\text { Variable } \\
\text { Regression 1 (DV: purchase intention) }\end{array}$} & $t$ & $p$ \\
$\begin{array}{l}\text { Ad display } \\
.28\end{array}$ & 3.14 & .002 \\
$\begin{array}{l}\text { Regression 2 (DV: perceived luxury) } \\
\text { Ad display }\end{array}$ & & \\
$\begin{array}{l}\text { Regression 3 (DV: purchase intention) } \\
\text { Perceived luxury }\end{array}$ & 4.45 & $<.001$ \\
Ad display & .54 & & \\
\hline
\end{tabular}

of 100 participants who rated these claims (using 5-point rating scales) on whether they considered these claims as indicative of high quality. The overall highest scoring claim ("Exclusive blend": $M=4.32$, $S D=0.68$ ), and the overall lowest scoring claim ("Basic blend": $M=1.83, S D=0.81$ ) were selected for the main study.

Based on these findings, display and claim were selected for the main study, and its horizontal counterparts were designed, ensuring that the latter were (except for line orientation) identical to the vertically-oriented displays (i.e., same line thickness, line shape, typeface design, and positioning of product information; see Fig. 2 for the finalized stimulus variants including brand claims).

\subsection{Participants and procedure}

A total of 120 customers (70 males, 50 females; mean age: 23.1 years; see Table 2) of a coffeehouse at a Dutch university campus participated in the main study. They were approached and asked if they would be willing to participate in a taste trial for a new coffee blend. Upon agreement they were taken to a dedicated area where the (framed) advertising poster was on display (for practical reasons, each day one of the four conditions of our $2 \times 2$ between-subjects design [i.e., one of the four posters; see Fig. 2] was on display). All taste sessions [on all four days] took place between 10 a.m. and 2 p.m. To ensure visual exposure to the poster, it was clearly pointed out that the taste test revolved around the advertised coffee. Next, the participants were handed a tablet, on which the survey could be filled out. While reading the introduction to the experiment, the regular, average- strength, house blend of the coffeehouse (which was selected in consultation with the baristas at the coffee place; and which was served with the exact same taste [coffee taste changes over time], volume, and temperature to each participant) was poured into a small blank (white) espresso cup which was handed to the participants. After tasting, participants filled out the questionnaire comprising the dependent measures, demographics, and control questions assessing daily coffee consumption and coffee drinking preferences. As these latter control questions did not influence product and taste evaluations, these will not be discussed further.

\section{Measures}

\subsection{Product evaluation}

Luxury perceptions were measured with the items luxurious, prestigious, chic, exclusive, cheap (reverse coded), and standard (reverse coded) (Cronbach's alpha $=.89$ ). Participants indicated (for all measures, 7-point rating scales were used) to what extent they considered these items applicable to the sampled coffee.

Quality perceptions were measured with the statements: 'I believe that this coffee is of good quality', 'I believe that this coffee brand will outperform other coffee brands', and 'I think this coffee contains unique quality features'. (Cronbach's alpha $=.86$ ).

\subsection{Taste evaluation}

Taste intensity was measured with the items strong, powerful, intense, and weak (reverse coded) (Cronbach's alpha $=.87$ ). Participants indicated to what extent they considered these items descriptive of the coffee taste.

Taste liking was measured with the statements 'This coffee tastes good', 'This coffee is tasty', and 'this coffee is delicious' (Cronbach's alpha $=.91)$.

\subsection{Purchase intention}

Purchase intention was measured with the single item 'I would consider buying this product in the supermarket'.

\subsection{Consequences of coffee consumption}

Finally, in order to test perceived consequences of coffee consumption, participants indicated to what extent they felt that the sampled coffee increased concentration, alertness, focus, and arousal (Cronbach's alpha $=.82$ ).

\section{Results}

Analyses of variance with ad display (vertical versus horizontal) and brand claim (exclusive versus basic blend) as independent variables, and respectively luxury and quality perceptions, taste intensity and taste liking, purchase intention, and consequences of coffee

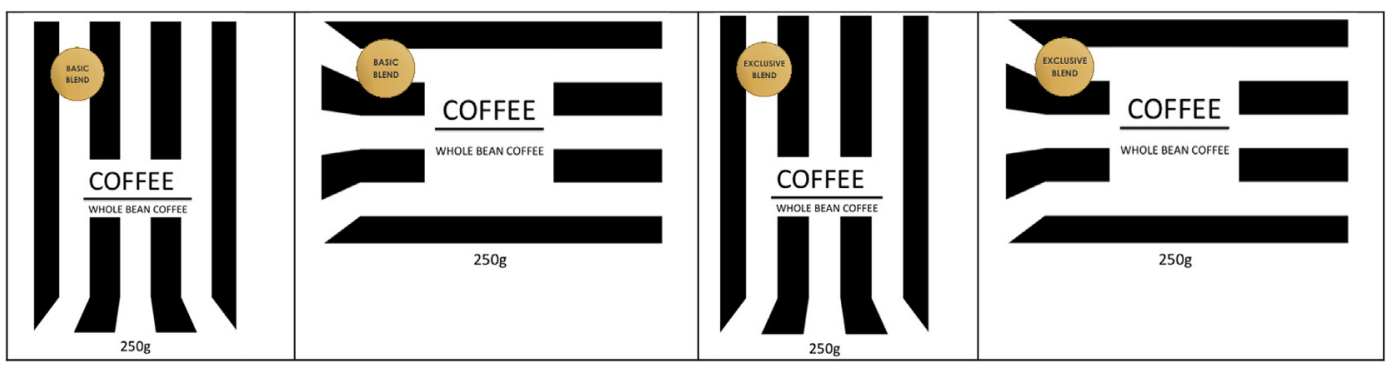

Fig. 2. The finalized ad display variants used in the main study. (left two panels: 'basic blend' claim; right two panels: 'exclusive blend' claim). 
consumption as dependent variables were performed.

\subsection{Product evaluation}

\subsubsection{Perceived luxury}

Confirming H1a, the main effect of ad display on luxury impressions was significant $\left(F(1,114)=20.02, p<.001, \eta^{2}=0.15\right)$, showing that participants perceived the coffee as more luxurious when associated with the vertically-oriented, rather than the horizontally-oriented, addisplay $(M=4.53, S D=1.20$ versus $M=3.62, S D=1.05)$. The effect of claim was non-significant ( $F<1$, ns), neither was the interaction between display and claim $\left(\mathrm{F}(1,114)=3.01, p=.09, \eta^{2}=0.03\right)$.

\subsection{Quality perception}

As for (related) quality perceptions (strongly correlated to perceived luxury; $r=0.82, p<.01$ ), the main effect of ad display was again significant $\left(F(1,114)=20.82, p<.001, \eta^{2}=0.15\right)$, showing that (in line with $\mathrm{H} 1 \mathrm{~b}$ ) quality perceptions were enhanced when the coffee was associated with the vertically oriented, rather than the horizontallyoriented, ad-display $(M=4.76, S D=1.28$ versus $M=3.74$, $S D=1.21)$. This time, the effect of brand claim was also significant $(F$ $\left.(1,114)=4.49, p=.04, \eta^{2}=0.04\right)$ with the 'exclusive blend', rather than the 'basic blend' claim enhancing quality perceptions $(M=4.48$, $S D=1.22$ versus $M=4.01, S D=1.42$ ). The interaction between visual display and claim was not significant $(F(1,114)=2.47, p=.12$, $\eta^{2}=0.02$ ).

\subsection{Taste evaluations}

\subsubsection{Taste intensity}

The main effect of ad display on taste intensity was, in line with H2a, significant $\left(F(1,114)=11.45, p=.001, \eta^{2}=0.09\right)$, indicating that the vertically oriented ad-display (as opposed to the horizontally oriented ad-display) enhanced taste intensity $(M=4.68, S D=1.15$ versus $M=3.88, S D=1.42$ ). The main-effect of brand claim on taste intensity was not significant $(F<1, n s)$. Likewise, the interaction effect between visual display and claim was not significant $(F<1, n s)$.

\subsubsection{Taste liking}

For taste liking (correlation with taste intensity: $r=0.47, p<.01$ ), the main effect of ad display was again (and in line with H2b) significant $\left(F(1,114)=19.74, p<.001, \eta^{2}=0.15\right)$; taste liking was higher when associated with the vertically oriented, rather than the horizontal oriented, ad-display $(M=5.41, S D=1.04$ versus $M=4,67$, $S D=1.27)$. Again, the effect of claim was non-significant $(F<1, n s)$, neither was the interaction between display and claim $(F<1, n s)$.

\subsection{Purchase intention}

In line with $\mathrm{H} 3$, the main effect of ad display on purchase intention was significant $\left(F(1,114)=9.76, p=.002, \eta^{2}=0.08\right)$ with the vertically-oriented ad-display enhancing purchase intentions $(M=5.07$, $S D=1.63$ ), as opposed to the horizontally-oriented ad-display $(M=4.08, S D=1.80)$. The effect of claim was not significant $(F<1$, $n s$ ), neither was the interaction between visual display and claim $(F<1, n s)$.

\subsection{Taste consequences}

The main effect of ad display on taste consequences was not significant $\left(F(1,114)=2.89, p=.09, \eta^{2}=0.02\right)$. The effect of claim was not significant either, neither was the interaction between ad display and claim (both $F$ 's $<1, n s$ ).

\subsection{Mediation analyses}

Finally, taking note of the predicted main effects of ad display on both luxury perceptions on the one hand and taste liking and product evaluation (i.e., purchase intention) on the other, we tested whether the effects of ad display on taste liking and purchase intention (the dependent variables indicative of positive taste and positive product evaluation respectively) are mediated by luxury perceptions as proposed in $\mathrm{H} 2 \mathrm{~b}$ and $\mathrm{H} 3$. That is, do consumers indeed like taste and product better (less) because the coffee is perceived as more (less) luxurious? To this end, mediation analyses were conducted (Baron \& Kenny, 1986). As already confirmed, the effects of ad display (independent variable) on luxury perceptions (the mediator) and taste liking and purchase intention (dependent variables) were significant (Tables 3 and 4, regressions 1 and 2). Crucially, for mediation to apply, the effect of ad display on taste liking and purchase intention should no longer be significant when perceived luxury is added to the regression analysis as a predictor of these latter measures, while the effect of the mediator (perceived luxury) should be significant. Results show that these criteria are partly met for taste liking (the effect of ad display is reduced but still significant) and fully for purchase intention (see Tables 1 and 2, regression 3). Hence, these findings suggest that participants more positively evaluate taste and product, because the ad display triggers luxury perceptions.

\section{Discussion}

The results presented clearly underscore the potential of abstract (i.e., non-figurative) visual cues when it comes to shaping product and taste evaluations; across our dependent measures, verticality cues (i.e., vertical orientation) positively influenced both product and taste evaluations. Although effects of vertical orientation on product evaluations have been demonstrated previously (e.g., Van Rompay et al., 2012), to our knowledge, this study is the first one to show that this type of verticality cues can also modulate specific taste sensations (taste intensity) and taste liking.

Our findings also underscore the relevance of the embodied cognition framework for brand and product positioning practice. This is all the more apparent when realizing that the impact of our verticality manipulation was much stronger compared to the more traditional brand claim manipulation (which only influenced product quality evaluation). As such, this study also confirms the idea that triggering consumer-generated meanings via design may well be a more successful strategy compared to enforcing meanings on consumers via traditional textual elements such as claims and slogans (cf. Krishna, 2012).

Specifically, our findings confirm the importance of verticality cues vis-à-vis a luxury brand strategy. Based on the embodied cognition framework and previous research demonstrating effects of verticality on luxury perceptions (Van Rompay et al., 2012), we argued that portraying verticality cues in an ad display should enhance luxury perceptions, evaluations of taste intensity, and evaluations indicative of taste and product liking (coffee tastiness and purchase intention respectively). Findings confirmed these predictions, thereby also demonstrating crossmodal correspondences between visual perception and taste (Spence, 2011, pp. 971-995). Furthermore, mediation analyses confirmed that effects of vertical orientation on purchase intention in particular were mediated by luxury perceptions. Hence, customers evaluated the product more positively because of (verticality-induced) luxury perceptions induced by the ad display.

Considering the weak effects of the brand claim manipulation, it should come as no surprise that we did not find evidence for effects of (in)congruence between ad display and brand claim (as proposed in H5). In all likelihood, our visual (and admittedly more salient) design manipulation overshadowed effects of the brand claim manipulation. Additionally, the predicted effects of vertical orientation on consequences of coffee consumption did not transpire. Arguably, assessing 
consequences of coffee consumption entails an additional step of product evaluation, involving a more abstract assessment (involving psychological rather than sensorial impressions) when compared to more concrete taste evaluations. Alternatively, it might of course be the case that the time span from tasting to evaluation of consequences was too short, and that a longer time span is needed for such effects to transpire.

In terms of future research, it would also be interesting to explore how verticality cues may be applied across different types of brand manifestations (ranging from packaging and advertising design to store design). As a matter of fact, Nespresso (in their 'high' design campaign) not only used verticality cues in their advertisements, at the same time a stress on verticality was also apparent from their brand stores and from their vertically-oriented cup dispensers. Note that such widespread applications of verticality across different types of design and architecture are also evident on a more abstract societal level. Think for instance of expensive, high-end top floor (or roof-top) restaurants and (cocktail-) bars or, reversely, of outlet departments in the basements of retail stores. And why do penthouse apartments located on the top floor always come with a premium price (despite drawbacks such as longer elevator times and higher risks in case of fire)? Is a 'nice' view the only compensation for these drawbacks, or does living high above the 'common people' resonate with experiences of power and pride?

Of further relevance here is research by Meyers-Levy and Zhu (2007) who manipulated verticality indoors by manipulating ceiling height. Their findings showed that higher ceilings activate (i.e., prime) freedom-related constructs. In line with this finding, Fischl and Garling (2008) found that ceiling height ranks among the most important architectural elements that influence psychological well-being. In other words, apart from triggering constructs and feelings related to luxury or power, verticality may also be valued because of its relatedness to positive affect (e.g., 'I'm down', 'feeling up', or 'I'm in heaven'), freedom, and wellbeing.

As these examples show (e.g., 'I'm in heaven' or 'I'm down'), verticality may not only be linked to orientation (as in the current study), but also to positioning of elements (e.g., a logo, claim or picture) along the vertical dimension (see Cian, 2017 for a review). For instance, confirming the common association between coming out on top and being all-powerful, Schubert (2005) showed that animals are perceived as stronger (i.e., more powerful) when depicted in the upper, rather than the lower part, of a computer screen. Although admittedly speculative, vertical orientation might correspond to the notion of upward movement (i.e., the process of going up) whereas vertical positioning rather corresponds to the destination of the target (i.e., the coming out on top). Follow-up research could assess this assumption by, for instance, investigating whether manipulations such as the vertical lines in the current study indeed trigger mental simulations of 'going up', and perhaps corresponding (upward) eye movements. As a matter of fact, previous research has demonstrated that visual product cues within advertisements (such as the subtle manipulation of orienting a product toward a consumer's dominant hand) can facilitate mental simulations and evoke motor responses (Elder \& Krishna, 2012).

In terms of shortcomings and limitations, it is of course true that our research deals with first impressions only. In other words, do effects of verticality cues still transpire after repeated exposure to product-displays such as packaging designs and posters, or do such design effects fade out? On the other hand, one could also argue that the results observed in our study (occurring after a single prime and within a timespan of only a few minutes) are very promising, and might be even more pronounced when exposure to the prime is repeated (e.g., when verticality cues are embedded in the corporate visual identity of an organization in a more structural manner).

Additionally, it is of course true that our visual manipulation was much more pronounced than our brand claim manipulation. On the other hand, this might be one of the key benefits of incorporating visual cues in promotion materials: precisely because they are of a visual nature and subtler as they do not enforce meanings on consumers, they may take in a prominent position without evoking reactance or negatively affecting product and brand evaluation (cf. Krishna, 2012).

Another shortcoming relates to the fact that apart from line orientation, the ad display itself also came in either a portrait or landscape format. Although this was a deliberate choice (so as to further accentuate line orientation), our findings do not allow us to disentangle effects of these two related, yet distinct, design factors. And although care was taken to design a horizontal display variant which would be identical (expect for line orientation) to the vertical variant, the ad displays also differed slightly in terms of, for instance, use of white space surrounding product information.

Furthermore, although verticality can (and has been) applied across different design factors, it remains to be seen whether, for instance, small-scale applications of verticality cues in soda cans are as effective as the more salient and 'in your face' verticality cues embedded in the larger scale ad displays used in the current research. Additionally, in the current study, the ad display was pointed out to customers upon introducing the study in order to ensure exposure to the verticality manipulation. Obviously, consumer attention is usually not (explicitly) drawn to visual cues portrayed on, for instance, product packaging in everyday encounters with products.

Finally, although research indicates (in line with the results reported here) that visual design factors in packaging are highly influential with respect to consumers' purchase intentions (Ares, Besio, Giménez, \& Deliza, 2010), care should be taken that the gap between expectations and actual consumption experiences does not become too large (i.e., a mismatch between expectations elicited by the package or display and taste sensations 'blocking' sensation transfer [Skaczkowski et al., 2016]). For instance, a display suggestive of a strong taste may harm, rather than boost, taste intensity evaluation when the product does not deliver at all (e.g., a low-caffeine smooth-tasting coffee blend; see also Schifferstein, Kole, \& Mojet, 1999; Van Rompay \& Groothedde, in press).

In concluding, this research builds forth on previous studies by showing that effects of verticality cues can have more far-reaching consequences than merely influencing (cognitive) associations as shown previously, but that such cues can actually impact taste experiences. As such, these findings testify to the importance of the embodied cognition framework for marketing practice and design.

\section{References}

Ares, G., Besio, M., Giménez, A., \& Deliza, R. (2010). Relationship between involvement and functional milk desserts intention to purchase. Influence on attitude towards packaging characteristics. Appetite, 55(2), 298-304.

Arnheim, R. (1974). Art and visual perception: A psychology of the creative eye. Berkeley, CA: University of California Press.

Baron, R. J., \& Kenny, D. A. (1986). The moderator-mediator variable distinction in social psychological research: Conceptual, strategic, and statistical considerations. Journal of Personality and Social Psychology, 51(6), 1173-1182.

Barsalou, L. W. (1999). Perceptual symbol systems. Behavioral and Brain Sciences, 22(4), 577-609.

Barsalou, L. W. (2008). Grounded cognition. Annual Review of Psychology, 59, 617-645.

Becker, L., van Rompay, T. J. L., Schifferstein, H. N., \& Galetzka, M. (2011). Tough package, strong taste: The influence of packaging design on taste impressions and product evaluations. Food Quality and Preference, 22(1), 17-23.

Cian, L. (2017). Verticality and conceptual metaphors: A systematic review. Journal of the Association for Consumer Research, 2(4), 444-459.

Deng, X., \& Kahn, B. E. (2009). Is your product on the right side? The 'location effect' on perceived product heaviness and package evaluation. Journal of Marketing Research, 46(6), 725-738.

Deroy, O., Crisinel, A. S., \& Spence, C. (2013). Crossmodal correspondences between odors and contingent features: Odors, musical notes, and geometrical shapes. Psychonomic Bulletin \& Review, 20(5), 878-896.

Elder, R. S., \& Krishna, A. (2012). The "visual depiction effect" in advertising: Facilitating embodied mental simulation through product orientation. Journal of Consumer Research, 38, 988-1003.

Fischl, G., \& Garling, A. (2008). Identification, visualization, and evaluation of a restoration-supportive built environment. Journal of Architectural and Planning Research, 25(3), 254-269.

Huber, J., \& McCann, J. (1982). The impact of inferential beliefs on product evaluations. Journal of Marketing Research, 19, 324-333.

Kapferer, J. N., \& Bastien, V. (2009). The luxury strategy: Break the rules of marketing to 
build luxury brands. London: Kogan Page Ltd.

Kastanakis, M. N., \& Balabanis, G. (2012). Between the mass and the class: Antecedents of the "bandwagon" luxury consumer behaviour. Journal of Business Research, 65(10), 1399-1407.

Krishna, A. (2012). An integrative review of sensory marketing: Engaging the senses to affect perception, judgment and behaviour. Journal of Consumer Psychology, 22, 332-351.

Lakoff, G., \& Johnson, M. (1980). Metaphors we live by. Chicago, IL: The University of Chicago Press.

Lakoff, G., \& Johnson, M. (1999). Philosophy in the flesh. New York, NY: Basic Books.

Machiels, C. J. A., \& Orth, U. R. (2017). Verticality in product labels and shelves as a metaphorical cue to quality. Journal of Retailing and Consumer Services, 37 195-20.

Meyers-Levy, J., \& Zhu, R. (2007). The influence of ceiling height: The effect of priming on the type of processing that people use. Journal of Consumer Research, 34, 174-186.

Osgood, C. E., Suci, G. J., \& Tannenbaum, P. H. (1957). The measurement of meaning Urbana, IL: University of Illinois Press.

Peracchio, L. A., \& Meyers-Levy, J. (2005). Using stylistic properties of ad pictures to communicate with consumers. Journal of Consumer Research, 32(1), 29-40.

Pinson, C. (1986). An implicit product theory approach to consumers' inferential judgments about products. International Journal of Research in Marketing, 3, 19-38.

Piqueras-Fiszman, B., \& Spence, C. (2012). The influence of the feel of product packaging on the perception of the oral-somatosensory texture of food. Food Quality and Preference, 26(1), 67-73.

Piqueras-Fiszman, B., \& Spence, C. (2015). Sensory expectations based on product-extrinsic food cues: An interdisciplinary review of the empirical evidence and theore tical accounts. Food Quality and Preference, 40, 165-179.

Raghubir, P., \& Krishna, A. (1999). Vital dimensions in volume perception: Can the eye fool the stomach? Journal of Marketing Research, 36, 313-326.

Reber, R., Schwarz, N., \& Winkielman, P. (2004). Processing fluency and aesthetic pleasure: Is beauty in the perceiver's processing experience? Personality and Social Psychology Review, 8, 364-382.

Schifferstein, H. N. J., Kole, A. P. W., \& Mojet, J. (1999). Asymmetry in the disconfirmation of expectations for natural yogurt. Appetite, 32(3), 307-329.

Schubert, T. W. (2005). Your highness: Vertical positions as perceptual symbols of power. Journal of Personality and Social Psychology, 89(1), 1-21.

Skaczkowski, G., Durkin, S., Kashima, Y., \& Wakefield, M. (2016). The effect of packaging, branding and labeling on the experience of unhealthy food and drink: A review. Appetite, 99, 219-234.

Spence, C. (2011). Cross-modal correspondences: A tutorial review: Attention, Perception, \& Psychophysics, Vol. 73.

Van Rompay, T. J., De Vries, P. W., Bontekoe, F., \& Tanja-Dijkstra, K. (2012). Embodied product perception: Effects of verticality cues in advertising and packaging design on consumer impressions and price expectations. Psychology and Marketing, 29(12) 919-928.

Van Rompay, T. J. L., \& Groothedde, S. (2019). The taste of touch: Enhancing saltiness impressions through surface texture design. Food Quality and Preference. https://doi. org/10.1016/j.foodqual.2018.11.003 (in press).

Van Rompay, T. J. L., Hekkert, P., Saakes, D., \& Russo, B. (2005). Grounding abstract object characteristics in embodied interactions. Acta Psychologica, 119, 315-351.

Van Rompay, T. J. L., \& Ludden, G. D. S. (2015). Types of embodiment in design: The embodied foundations of meaning and affect in product design. International Journal of Design, 9(1), 1-11.

Van Rompay, T. J. L., \& Pruyn, A. T. H. (2011). When visual product features speak the same language: Effects of shape-typeface congruence on brand perception and price expectations. Journal of Product Innovation Management, 28, 599-610.

Van Rompay, T. J. L., Pruyn, A. T. H., \& Tieke, P. (2009). Symbolic meaning integration in design and its influence on product and brand evaluation. International Journal of Design, 3, 19-26.

Velasco, C., Woods, A. T., Petit, O., Cheok, A. D., \& Spence, C. (2016). Crossmodal correspondences between taste and shape, and their implications for product packaging: A review. Food Quality and Preference, 52, 17-26.

Zhang, Y., Feick, L., \& Price, L. (2006). The impact of self-construal on aesthetic preference for angular versus rounded shapes. Personality and Social Psychology Bulletin, 32(6), 794-805. 